\title{
Pistas somáticas para um estudo da corporeidade: uma aprendizagem das sensações
}

\author{
Patricia de Lima Caetano ${ }^{\star}$ \\ Universidade Federal do Ceará, Fortaleza, CE, Brasil
}

\begin{abstract}
Resumo
Este texto pretende apresentar algumas pistas para um estudo da corporeidade a partir da metodologia de aprendizagem somática evidenciando-a como uma aprendizagem do/pelo corpo vivido e experimentado através da habitação de sua dimensão material intensiva e heterogênea, produtora de alteridades espaço-temporais. Para tanto, nos aproximaremos da abordagem somática Body Mind Centering. Serão apresentados relatos de experiências registrados em um diário de bordo e em entrevistas que procurarão evidenciar a natureza estético-sensível do corpo como impulsionadora de um aprendizado pela via das sensações. Os relatos compõem um campo investigativo no qual o corpo, em experimentação de si, se faz bússola de um processo errante de buscas pela legitimação do corpo enquanto realidade plena, potente e vital.
\end{abstract}

Palavras-chave: corporeidade; educação somática; aprendizagem experimental; sensações; alteridade.

\section{Somatic clues for a study of the corporeity: a learning of sensations}

\begin{abstract}
This text intends to present some clues for a study of the corporeity from the methodology of somatic learning evidencing it as a learning of / by the lived and experienced body through the habitation of its intensive and heterogeneous material dimension, producer of space-time othernesses. To do so, we will get closer to the somatic approach developed by Body Mind Centering. We will present accounts of experiences recorded in a logbook and in interviews that will search to highlight the aesthetic-sensitive nature of the body as a propellor of learning through sensations. The accounts set out an investigative field in which the body, in self-experimentation, become the compass of an errant process of searching for the legitimation of the body as a full, potent and vital reality.
\end{abstract}

Keywords: corporeity; somatic education; experimental learning; sensations; otherness.

Ao longo deste texto, apresentaremos algumas pistas para um estudo da corporeidade a partir da metodologia de aprendizagem somática, evidenciando-a como uma aprendizagem experiencial que se dá pela via das sensações por meio de um contágio estético-sensível entre corpo e ambiente. Em tal aprendizagem, a habitação do corpo em sua dimensão material instável e heterogênea, promove a abertura da matéria-corpo, tornando-a produtora de alteridades espaço-temporais. Por meio de relatos de experiência, será possível evidenciar a natureza sensível e cambiante da matéria-corpo, como um aspecto impulsionador do aprendizado de si e do mundo, em um processo necessariamente contínuo e pulsante de re-configuração próprio ao vivo. Tais pistas nasceram do interesse em aprofundar um olhar acerca da abordagem somática Body Mind Centering ${ }^{\mathrm{TM}}{ }^{1}{ }^{1}$ interesse este que se concretizou ao longo dos percursos investigativos de uma tese de doutorado realizada no Programa de Pós-Graduação em Artes Cênicas da UFBA. ${ }^{2}$ Longe de apresentar uma prescrição ou uma receita, apresentaremos aqui algumas pistas advindas de um campo investigativo no qual o corpo em experimentação de si, se fez bússola de um processo errante de buscas pela legitimação do corpo enquanto realidade plena, potente e vital.

Conforme veremos mais adiante, a noção de corpo compreendida e abordada pelo campo da educação somática em muito se aproxima da definição de corporeidade

\footnotetext{
^Endereço para correspondência: Universidade Federal do Ceará, Instituto de Cultura e Arte - ICA. Campus da UFC Pici. Fortaleza, CE - Brasil. CEP 60440900.E-mail: tita.caettana@gmail.com

'Também designado pela sigla BMC

${ }^{2}$ Tese defendida em março de 2012 na cidade de Salvador, no PPGAC/ UFBA. Ver Caetano (2012).
}

apresentada pelo pesquisador francês Michel Bernard (2001). Ao evocar a categoria corporeidade em contraposição subversiva à categoria corpo, Bernard quer pensar uma experiência corporal diferenciada, heterogênea e mutante, composta por forças "pulsionais" e "intensidades díspares e cruzadas". Segundo ele, a categoria corpo, enraizada no ocidente, designaria uma experiência corporal caracterizada pela homogeneidade e estabilidade, através da qual é possível estabelecer uma relação corpórea objetificada, controlada e massificada. Ao reconhecer a complexidade lingüística, ontológica e performativa que envolve a terminologia "corpo" dentro do contexto cultural ocidental, Bernard (2001, p. 24), aproximando-se da corporeidade, afirmará que "a negação teórica do conceito tradicional de 'corpo' é, sobretudo, uma reação e uma proteção imunológica contra a visão filosófica que este conceito veicula; enfim, um verdadeiro 'anticorpo' no duplo sentido da palavra". O modelo tradicional de corpo, tal qual é conhecido no Ocidente, longe de ser um dado natural, fruto de uma experiência universal, se encontra atrelado a um modelo de existência carregado de uma visão ordenadora do mundo que, segundo Bernard (2001, p. 20), é típica do "projeto tecno-científico de um capitalismo triunfante".

Iniciada em fins do século XIX e intensificada ao longo do século XX, a crise do sujeito moderno no Ocidente se fez visível a partir de inúmeros movimentos imbuídos pelo desejo de religar arte e vida em diversos campos políticos, sociais, culturais e artísticos. Neste cenário, o corpo começou a ganhar um novo estatuto. Nesta mesma época é possível perceber nos países do norte europeu e nos Estados Unidos o advento do Movimento Corporalis- 
ta, que mais tarde veio a ser designado por Educação Somática. Inseridos em diferentes áreas de conhecimento, diversos pesquisadores desenvolveram técnicas, práticas e métodos corporais pautados em uma semelhante abordagem do complexo corpo-mente envolvendo domínios como o sensorial, o cognitivo, o motor e o afetivo (FORTIN, 1999, p. 40). Dentro deste campo de conhecimento, a matéria corpórea passou a ser matéria prima para a construção de um conhecimento de si e do mundo.

A noção de soma que dá origem ao termo somática(o) foi utilizada pela primeira vez pelo pesquisador Thomas Hanna em 1976, em seu artigo "The field of somatics", no intuito de evocar um corpo vivido e experienciado a partir da percepção daquele que experimenta o corpo. $\mathrm{O}$ soma enquanto corpo experienciado se opunha à noção de corpo objetificado e mecanizado. A partir de então, o corpo entendido desde a perspectiva somática é aquele que se experimenta ao mesmo tempo em que experimenta o mundo, ou, experimenta o mundo ao mesmo tempo em que se experimenta. Portanto, o soma jamais poderá ser compreendido ou abordado como um objeto inerte, passivo, secundário e passível de controle ou docilização. Bem ao contrário, o soma é o corpo que experiencia, se experiencia e, gostaríamos de incluir aqui, gera experiência. Assim, o corpo como gerador de experiência é um criador de realidades. No encontro com o mundo, o soma (ou ainda, a corporeidade) é o corpo inacabado, processual e relacional, que se cria na experiência, ao mesmo tempo em que cria um mundo possível. Dentro desta perspectiva, mundo e corpo são realidades que somente existem por co-engendramento. Como poderemos observar mais adiante, gostaríamos de afirmar que para além da experiência fenomenológica pessoal de um sujeito que experimenta o mundo em primeira pessoa, a noção de soma desenvolvida pelas práticas somáticas, se aproxima intimamente das afirmações do filósofo José Gil (2004, p. 56) quando este nos apresenta o corpo como "metafenômeno", tanto visível quanto invisível, "feixe de forças" e "transformador de espaço-tempo".

A Educação Somática é um campo vasto composto por diferentes abordagens e técnicas. Cada qual com suas especificidades, possui em comum uma metodologia de investigação corpórea pautada pelo trabalho sobre a senso-percepção. Podemos citar algumas como a Eutonia, o Método Feldenkrais, a Técnica de Alexander, os Bartenieff Fundamentals, o Body Mind Centering, entre outras. No Brasil, podemos ainda considerar como pertencentes ao campo da Educação Somática, a metodologia Klauss Vianna e a Metodologia Angel Vianna de Conscientização do Movimento.

A partir de um exercício de alargamento dos sentidos, estas práticas somáticas atuam como propositoras de uma experiência de abertura à criação de um corpo "outro", expandindo os limites de suas organizações demasiadamente condicionadas em automatismos cristalizantes. De um modo geral, as práticas somáticas convidam o corpo a exercitar os sentidos fora do regime restrito da representação. Assim, a partir de um convite à experimentação dos sentidos no âmbito prismático das sensações, o corpo tem a oportunidade de experienciar o mundo e a si mesmo para além da representação de corpos, objetos e signos já dados. Olharemos para estas questões com mais cuidado a partir da metodologia somática do Body Mind Centering.

Criado pela norte americana Bonnie Bainbridge Cohen, o Body Mind Centering consiste numa anatomo-fisiologia experimental do corpo. Tal abordagem tem como proposição metodológica a experimentação dos sistemas corporais (sistema esquelético, muscular, endócrino, nervoso, sistema dos ligamentos e fáscias, sistemas dos órgãos, sistema dos fluidos, e os órgãos dos sentidos e a percepção) por meio da visualização, toque, movimento e sonorização. Além da experimentação dos sistemas corporais, esta abordagem também propõe o estudo e a experimentação das etapas ontogenéticas e filogenéticas do desenvolvimento do movimento, pressupondo "planos de contágio" em movimento entre humanos e não-humanos.

Diferente de outras abordagens somáticas, o Body Mind Centering não propõe um método centrado em exercícios corporais codificados, através dos quais se operaria uma reorganização do corpo na direção de um uso sensório-motor mais adequado previamente estabelecido. Trata-se aqui de uma aprendizagem eminentemente experimental através da qual o corpo compreendido em sua ontogênese perpétua explora os seus próprios meios de constituição tanto materiais e energéticos, quanto formais. Esta aprendizagem ocorre por meio da focalização senso-perceptiva sobre uma ou várias estruturas anátomo-fisiológicas (regiões teciduais constitutivas da matéria-corpo em sua pluralidade) implicadas num movimento determinado e em relação com o meio circundante. Por meio desta focalização, solicita-se fazer emergir uma paisagem de qualidades táteis e cinestésicas, de texturas diferenciadas em suas intensidades, assim como diversificados limiares energéticos. A partir de então, redesenha-se tanto o território corpóreo sentido pelo experimentador, como o espaço de projeção da cinesfera. ${ }^{3} \mathrm{O}$ espaço ao redor é modificado por meio da reverberação entre dentro e fora, somente possível pela ativação de uma qualidade porosa e vibrátil da pele e demais membranas do corpo. A partir desta ativação, as qualidades vibráteis do corpo e do ambiente podem se contagiar mutuamente.

Aqui tocamos na dimensão performativa do soma. Tal metodologia somática propõe que possamos experienciar o corpo e seus sistemas corporais por meio do embodyment. Assim, acompanhando os processos experienciais do corpo, sempre em atitude relacional com o ambiente, opera-se uma diminuição na preponderância da atenção analítica do eu-indivíduo, e uma outra qualidade de atenção, que Cohen chama "consciência celular" dos tecidos e/ou sistemas experimentados, ${ }^{4}$ ganha força

${ }^{3}$ Cinesfera é a esfera de espaço tridimensional ao redor do corpo dentro da qual acontece o movimento e cujas periferias podem ser alcançadas facilmente pelos membros esticados sem que precisemos mudar a nossa base de apoio. Ao nos movermos carregamos conosco a nossa cinesfera, transferindo-a para um novo ponto de apoio, como uma aura. Também denominada kinesfera, este conceito pertence ao Método Laban de Análise do Movimento. Para maiores informações vide Fernandes (2006).

${ }^{4}$ Segundo Cohen (2010), os sistemas e tecidos corporais são compostos por comunidades celulares. Verdadeiros conglomerados de células que possuem qualidades vibracionais específicas. 
de presença. Por meio de suas proposições, exploramos transitar desde a experiência celular até os sistemas corporais, direcionando a atenção para os diferentes tecidos do corpo e experimentando diferentes qualidades de movimento e estados de presença. ${ }^{5}$ Poderíamos afirmar que o embodyment ou a "corporalização" opera a entrada em um estado de atenção outro, um estado de sensação, por meio da captura de forças das matérias-corpo que, a partir de então, guiam os movimentos e gestos do experimentador no espaço. Neste processo, o experimentador entra em estado de devir. Ao deslocar-se do centramento de si, experimenta-se em deriva habitando as forças que o constituem. $\mathrm{O}$ corpo que se experimenta por meio do embodyment passa por várias etapas de investigação, transitando desde o estudo e visualização de imagens-representação do corpo, provenientes dos mapas da anatomia convencional ocidental (atlas anatômico), até chegar a experimentação de imagens-sensação ${ }^{6}$ moventes provenientes da vivência do experimentador-pesquisador em acompanhamento dos devires do corpo. Neste processo outras relações espaço-temporais entre corpo habitado e ambiente vivido emergem em meio a uma operação de modulação das sensações da matéria-corpo. O soma performatiza o espaço, performatiza o tempo, e performatiza a si em meio as alteridades que vivencia.

\section{Uma aprendizagem das sensações: relatos de um laboratório de investigação da corporeidade}

A partir de então, apresentarei três relatos de experiência provenientes de um laboratório de investigação da corporeidade realizado durante o desenvolvimento de minha pesquisa de doutorado. Neste laboratório, coloquei-me como pesquisadora-experimentadora da pesquisa e, numa atitude receptiva, procurei acompanhar meus próprios processos de aprendizagem da corporeidade em meio à participação em oficinas e nas aulas da formação profissional de BMC. ${ }^{7}$ Através de diários de bordo procurei observar e compreender minhas próprias experiências. ${ }^{8}$ Numa etapa seguinte, por meio da realização de entrevistas, pude confrontar minhas experimentações com as de outros participantes na formação profissional de BMC, onde busquei compreender este processo de aprendizagem de si e do mundo pela via das sensações. Por meio destes três relatos apresentarei um recorte deste laboratório.

Ao valorizar a experimentação da corporeidade no processo de construção do conhecimento, procurei reconhecer a dimensão intensiva do corpo, seus momentos moleculares e desestabilizantes, suas mutações e noma-

\footnotetext{
Ainda segundo Cohen (2010, p. 78), "cada célula é única. Uma grande variedade de células comunica entre si. As células de estrutura parecida formam entidades que funcionam como tecidos. Esses tecidos reagrupam-se em entidades mais vastas que funcionam como sistemas". As células compõem a dimensão micro do corpo, os sistemas corporais compõem a dimensão macro. A base desta abordagem somática pressupõe uma aprendizagem no nível micro-celular, tendo em vista que, "as células do corpo informam o cérebro tanto quanto o cérebro informa as células" (COHEN, 2008, p. 37).

${ }^{6}$ Os termos imagem-representação e imagem-sensação serão desenvolvidos mai adiante, no subtítulo "Pistas para um Estudo da Corporeidade".

Formação em Educador Somático pelo Movimento (Somatic Movement Educator-SME), credenciada pela The School for Body Mind Centering.

${ }^{8}$ Tornei-me, portanto, sujeito e objeto da pesquisa, o que justifica a partir deste momento do texto, esta escrita em primeira pessoa.
}

dismos, como processos importantes do conhecer e do re-configurar-se. Assim, a partir da prática somática do $\mathrm{BMC}$, intencionei perceber que, através da operação de desestabilização da dimensão demasiadamente organizada do corpo, é possível ver emergir uma corporeidade mutante feita de fluxos e intensidades. Neste processo, o experimentador pôde habitar um espaço limiar do corpo, um campo de forças da matériacorpo que é também um espaço de abertura à emergência da alteridade corpórea.

Os seguintes relatos apresentam a descrição das aulas relacionadas e as narrativas de experiências sensíveis, seguidas por breves reflexões. Tais reflexões apontam para algumas pistas para um estudo da corporeidade. Estas pistas aparecerão evidenciadas em meio às reflexões e posteriormente serão apresentadas separadamente.

\section{Diário de Bordo: Relato de experiência a partir de uma aula sobre o Sistema Esquelético na formação Profissional em BMC com a profa. Lulla Chourlin, na Cartoucherie, Paris, 2011}

Dia 24 de fevereiro de 2011 - Neste dia realizamos um trabalho sobre a cintura escapular. Observamos e reconhecemos a cintura escapular no esqueleto, como também sua figura representativa no atlas anatômico. Em duplas, tocamos e reconhecemos as estruturas ósseas da escápula, espinha escapular, clavícula, axônio, cavidade glenóide e processo coracóide. Após essa primeira fase de reconhecimento, Lulla nos propôs uma dinâmica em duplas. Uma pessoa devia pousar as duas mãos nas escápulas do parceiro. $\mathrm{O}$ parceiro deveria mobilizar os braços elevando-os e descendo-os. A pessoa que toca e a pessoa que é tocada deveriam sentir o movimento das escápulas. Elas sobem e abrem para as laterais como asas. Finalizada esta experimentação, houve ainda outra proposição em duplas. Deveríamos reconhecer as linhas de força entre os dedos da mão e partes da escápula e clavícula. Neste reconhecimento tocávamos cada dedo de cada vez e procurávamos sentir a conexão da linha de força com a parte correspondente na escápula e clavícula.

Quando fui tocada sentia a conexão na área correspondente, a presença, os micro-movimentos, os rearranjos dos tecidos em torno. Minha parceira começou tocando meus dedos com muita pressão. Havia muita força no toque e isso não me ajudava a sentir as linhas de força. Precisava de menos pressão, mais sutileza, mais leveza para conectar as linhas de força. Se eu sentia demais a pressão havia um certo incômodo que apagava as outras sensações mais sutis. Desconcentrava- me. Por vezes ela puxava o dedo para fora de meu corpo e isso me trazia para uma conexão ósseo-muscular. Não era essa conexão que queria acessar. Precisava de uma conexão invisivel, micro, granular. Pedi para ela diminuir a pressão e aí sim, eu comecei a sentir a tal conexão que desejava. Depois, ao me mover pelo espaço, foi muito interessante! A conexão braços-escápulas e a realidade presente desta região eram poderosíssimas. Maior do que qualquer outra região de meu corpo neste momento. Essa região começou a me mover. Ela me suspendeu do chão até a posição de pé. Não havia força muscular, nem intenção nas pernas, pés e bacia. Era real- 
mente o osso esterno, as escápulas e os braços que me suspendiam. Depois, eu me movia pelo espaço e só havia essa região no meu corpo. Eu era toda "asas", "enormes asas horizontais". Por vezes me sentia apoiada num espaço que se criava atrás de minhas escápulas. As escápulas pousavam neste espaço e eu flutuava neste suporte, enquanto o osso esterno apresentava a sua presença totalmente aberta ao espaço à sua frente-alta. Havia uma força que o puxava para cima. Por vezes, o esterno se deslocava com uma intencionalidade poderosa de avanço. Os braços mantinham-se o tempo todo sustentados no espaço, ora horizontal, ora vertical-alta, no entanto nunca pendiam para baixo. Havia uma força conectiva que vinha das escápulas e os sustentava neste imenso espaço ao redor de meu tronco e cabeça. Um espaço que se criava. Meus braços eram enormes. Meus braços, escápulas e esterno eram uma só grande presença viva, com suas autonomias. Eles jogavam entre si, funcionavam em íntima conexão. Os braços desenhavam enormes espirais de dentro para fora. As espirais tinham vida própria e me levavam pelo espaço. Eu não conseguia parar, sentia vertigem e por vezes náuseas. As espirais plainavam no espaço como asas enormes de uma águia branca. Assim eu as via, sentia e percebia. Meus braços, esterno e escápulas plainavam no espaço. Meu esterno avançava! Era como uma proa no ar! Minhas pernas praticamente não existiam, elas acompanhavam a unidade superior do corpo, viva! Imponente! Soberana! Não conseguia parar. Sentia náuseas. Precisei ficar um tempo no chão sentindo o fluxo no corpo. Depois, caminhei um pouco pelo espaço, mas ainda assim as espirais vieram fazendo meu corpo girar em vertigem. Pensei: preciso parar. Caminhei e relaxei os braços ao chão. Eles queriam ficar de novo suspensos no ar. Sentia o osso esterno em posição de avanço! Era enorme! Preciso desenhar!!

Neste relato é possível reconhecer que o toque com intenção de "querer fazer" impedia uma conexão mais fina com a dimensão intensiva das forças. Para além da conexão ósseo-muscular, havia ainda as linhas de forças entre os dedos das mãos e regiões específicas das escápulas e clavículas. Era preciso um toque com escuta que permitisse uma "atenção introspectivo-receptiva", ou ainda, uma escuta aos fluxos e micromovimentos do corpo. A partir do momento em que foi possível estabelecer uma conexão com as matérias do corpo em questão (procurando ouvir as relações entre dedos das mãos, escápulas e clavículas), suas presenças expressivas puderam advir. Eis que a "intencionalidade da matéria", - neste caso, matéria-cintura escapular, matéria-braços e matéria-mãos - suspendia o corpo do nível baixo ao alto do espaço. Ao experimentar a alteridade destas matérias, o "corpo-alteridade" se apresentava enquanto devir-asas que plainavam no suporte do espaço. Um espaço-suporte criava-se juntamente às asas. Havia ainda uma "intencionalidade da matéria-esterno" que impulsionava o peito em avanço fazendo-o deslocar-se à frente e ao alto. Eis que um "estado do corpo" modificado se apresentava em meio a espirais dos braços, estas eclodiam numa dinâmica de fluxo vertiginoso ininterrupto. Um "imaginário encarnado" em ação fazia emergir imagens-sensação: escápulas e braços como asas enormes de uma águia branca em espiral, ou ainda, esterno como proa que avança (vide figuras 1 e 2).

Fractal, Rev. Psicol., v. 29 - n. 2, p. 168-176, 2017
Figura 1 - Imagem-Sensação Esterno e Asas ou Avanços e Espirais. No original $30 \times 42 \mathrm{~cm}$. Giz de cera sobre papel.

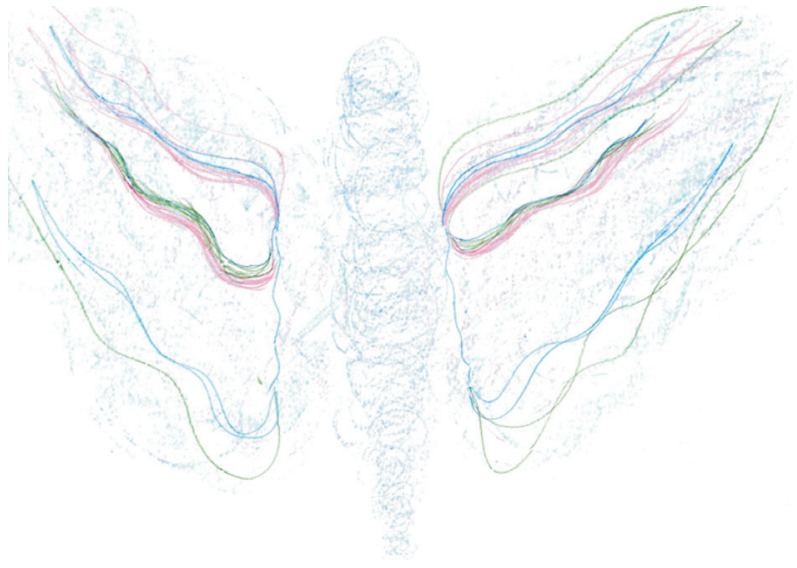

Figura 2 - Imagem-Sensação Esterno e Asas II ou Escápulas de Águia. No original 30 x $42 \mathrm{~cm}$. Giz de cera sobre papel.

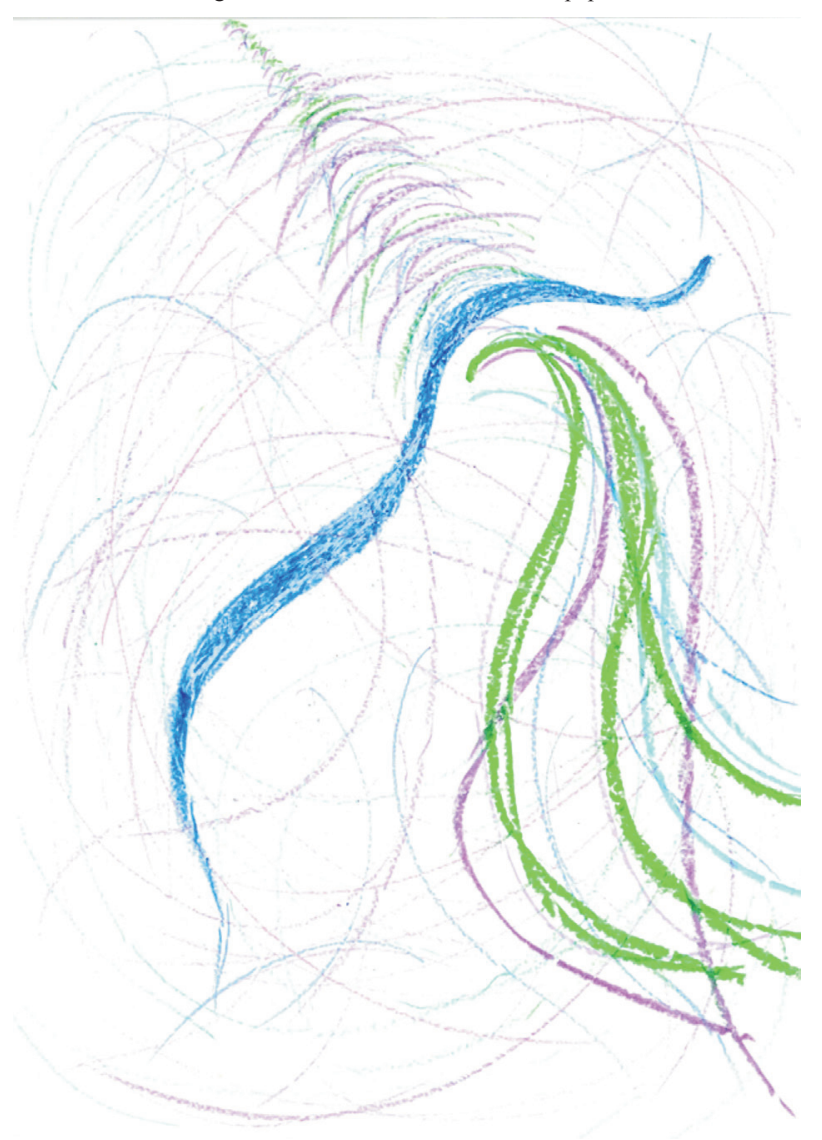

Entrevista com C. N. ${ }^{9}$ - Relatos de experiência a partir de duas aulas, uma sobre o Sistema dos Órgãos e outra sobre o Sistema Endócrino na formação

Profissional em BMC, na Cartoucherie, Paris, 2010

C.N. afirma que a partir dos procedimentos do BMC ela tem a oportunidade de colocar uma luz em lugares do corpo que ela não teria como fazer sozinha. Então, ao conectar a respiração celular ${ }^{10}$ nestes lugares, ela pode

\footnotetext{
${ }^{9}$ C. N. é dançarina profissional e coreógrafa. Reside na França e participou da Formação Profissional em BMC (Somatic Movement Educator).

${ }^{10} \mathrm{Em} \mathrm{BMC}$, a respiração celular consiste no primeiro esquema orgânico de movimento das células vivas. Ela designa a troca gasosa realizada graças ao vai e vem dos líquidos através das membranas. Aparece primeiro nos oceanos terrestres e se perpetua em cada uma de nossas células mergulhadas no mar interior do corpo. A Respiração Celular é um procedimento prático realizado nas aulas de BMC. A integração de uma experiência (embodiment) no nível celular repousa sobre a respiração.
} 
observar o que modifica no corpo. Ela traz dois exemplos de experimentação de uma modificação intensa do corpo a partir das explorações do BMC.

Por exemplo, durante o sistema dos órgãos, nós começamos com Frederica, nós trabalhamos sobre o tubo digestivo, e então ela começou a falar da língua, da boca, e de fato, na medida em que ela falava, eu estava em contato com esse tubo digestivo. E agora como eu estou falando sobre o tubo digestivo o estado de meu corpo... eu quero dizer que há alguma coisa que ralenta em mim verdadeiramente, e que faz que num momento dado eu tenha me fundido no solo por que enfim....

Neste momento, enquanto C.N. descreve a experiência, a sua fala se modifica e ganha outra textura, o gestual de seu corpo e toda a sua postura se transforma ganhando uma qualidade densa, mole e escorregadia para baixo, na direção do solo. Um corpo-alteridade se apresenta em meio à conversa. É importante esclarecer que C.N. se encontrava sentada em uma cadeira no momento em que faz seu relato. A modulação das sensações se põe em ação na medida em que ela fala. Ao falar C.N. reconecta e acessa novamente estas matérias. Nota-se então que, ao percorrer a geografia interior do tubo digestivo repleta de texturas e densidades específicas, C.N. é lançada em um estado do corpo embalado pelas sensações ralentadas.

E em relação à mesma experiência:

Há alguma coisa, você vê? Eu não posso, eu não posso permanecer sentada normal... e como eu me encontrava no chão, de fato eu ouvia, mas era... ela estava longe, era como se eu estivesse num lugar muito longe no meu corpo, muito profundo e eu me encontrava realmente sobre o chão com essa noção de peso de todo o sistema do tubo digestivo, e você vê? Falar me reconecta diretamente a essa experiência em termos de sensação no corpo que faz com que eu não fique sentada.

\section{E ela continua,}

Então eu permaneci um momento sobre o chão sem me mover, e verdadeiramente numa respiração muito, muito lenta sentindo isso que sinto agora, esse peso em tudo, alguma coisa, você vê? Que se dispersa, mas que não é o líquido, é mais uma matéria boooooaaaaarrrrrr..., enfim....como isso. E num momento dado meu corpo se vira, eu fico de cócoras, e num outro momento meu corpo se vira e eu me encontrei deitada, mas o modo como eu me virei, eu senti que a iniciação do movimento vinha desse lugar do tubo digestivo e então quando eu me virei.. mas era uma sensação.... todo o resto seguia, todos os músculos, toda a estrutura do esqueleto, eles seguiam de fato e aaaaaaahhhhhhaaaa... uma espécie de relaxamento uuuhhhhhoooooaaaaa... agora eu o encontro, você sabe, eu não estou no chão mas eu sinto verdadeiramente. Foi interessante para mim contatar todas essas sensações e o que isso induz no meu corpo em termos de movimento, de qualidade, de gosto no corpo.

Nesta continuidade de seu relato, presencia-se uma fineza perceptiva e sensitiva. C.N. discrimina as sensações provenientes de uma matéria que se dispersa e que, no entanto, possui uma qualidade mais densa que o líquido.
Em exercício de "atenção introspectivo-receptiva" C.N. habita um lugar muito profundo e tem dificuldades de ouvir a voz da facilitadora. Ao relatar uma experiência passada que se atualiza no instante da fala, passado e presente se misturam. Por vezes, C.N. tem dificuldade de nomear tais sensações. Ao adentrar os estados do corpo provenientes da matéria-tubo digestivo, na falta de uma palavra que as nomeie, C.N. emite sons encarnados embalados pela "modulação das sensações". Neste mergulho profundo nos umbrais da carne, C.N. presencia deslocamentos do corpo iniciados por uma "intencionalidade da matéria". Uma intencionalidade do tubo digestivo leva as demais estruturas do corpo tais como, musculaturas e estrutura esquelética, a um deslocamento sequencial no espaço. Ao presenciar C.N. sendo tomada pelas sensações provenientes da matéria enquanto relata sua experiência, evidenciou-se aqui a realização de uma capacidade de acesso à matéria-tubo digestivo e suas qualidades sensíveis. Tal evidência pôde nos apontar para a possibilidade de constituição de uma "cartografia do corpo afetivo". A partir das experimentações em BMC, C.N. despertou a potência de afetar e ser afetada pelo tubo digestivo. Ao percorrer sua geografia interna sensível, uma ferramenta afetiva de acesso à matéria-tubo digestivo foi então desenvolvida. Esta matéria poderá ser acessada a qualquer momento e se tornou uma ferramenta de conexão.

C.N. continuou descrevendo um segundo exemplo de experimentação intensa de uma modificação corpórea que lhe trouxe sensações diferenciadas.

Nós trabalhamos muito com o som ao nível das glândulas no módulo do sistema endócrino. Um dia nós trabalhamos com um ponto reflexo da glândula pituitária que se situa na cabeça, mais no interior. Então nós fizemos uma experiência onde nós colocamos cabeça apoiada com cabeça e nós fizemos sons com a pessoa. Quando nós nos separamos, de fato eu senti todo meu campo magnético em torno do corpo. Eu te situo aqui dois extremos de exploração guiada que me trouxeram sensações diferentes em relação à focos diferentes, porque aqui nós estávamos sobre as glândulas e a glândula se relaciona com a energia e o campo magnético. Aqui era realmente aahahaahhhhh..., eu sentia como se eu pudesse tocar o campo que estava em volta de minha cabeça com minhas mãos. De fato foi muito forte. A sensação do campo é uma vibração muito fina que se difunde em torno de si, que se difundiu em torno de minha cabeça. E era realmente palpável para mim, eu te falo: foi forte!

Diante destes dois exemplos, C.N. afirma que o seu estado de presença corpórea ("estado do corpo"), quando ela contatou o tubo digestivo, era completamente diferente do estado de presença corpórea proporcionado pelo contato ao campo magnético difundido pela glândula pituitária.

Neste relato, presencia-se, mais uma vez, uma experimentação ao nível da "modulação das sensações", no entanto, completamente diferente da primeira. Para acessar a glândula no interior da cabeça uma "atenção introspectivo-receptiva" foi estabelecida no âmbito de uma dinâmica de contato ao outro. Tal experiência com a glândula pituitária desencadeou sensações de um campo magnético: uma vibração muito fina que se difundia em 
torno da cinesfera. Através do trabalho das sensações, C.N. pôde então reconhecer a localização deste campo em torno de sua cabeça e poderia inclusive tocá-lo com suas próprias mãos. A sensação encarnada se tornou concreta posto que vivida pela própria matéria-corpo. A "cartografia do corpo afetivo" pôde ser então amplificada a partir de mais uma experimentação sensível e corporificada no nível das glândulas endócrinas.

Segundo C.N., quase todas as explorações guiadas nas proposições do BMC a levam a abrir portas desconhecidas no corpo e, a partir do momento em que isso ocorre, o corpo responde. Nestes momentos ela pode vivenciar experiências com o movimento que não são voluntárias. Não se trata então de dizer "agora eu faço três passos, e ando, e giro o tronco". Segundo C.N., cada sistema ou tecido permitirá o acesso a uma porta específica: "efetivamente, se você está numa exploração guiada sobre o tubo digestivo, não é a mesma porta que se você estiver trabalhando sobre o ponto reflexo ao nível das glândulas da cabeça". Cada sistema vai trazer um colorido diferente, pois como ela diz "se eu estou no tubo digestivo, eu estou num peso que verdadeiramente transborda, se derrama e até o continente do corpo é embarcado por isso".

\section{Pistas Somáticas para Um Estudo da Corporeidade}

Trouxemos aqui três relatos de experimentações e reflexões no âmbito da corporeidade. Estes relatos compuseram um campo de pesquisa e investigação muito mais amplo. Os exemplos de experiências concretas que foram descritos tanto nos diários de bordo quanto nas entrevistas constituíram informações relevantes no reconhecimento de algumas pistas somáticas para um estudo da corporeidade que se configurou através de uma aprendizagem das sensações. Ao longo destes relatos foi possível perceber a existência de experiências comuns e informações que se cruzavam, como também, modos singulares de apreensão e experimentação da corporeidade. A partir de então, apresentaremos algumas destas pistas.

Nomeamos a primeira pista para um estudo da corporeidade de "Prudência Somática". Esta diz respeito às operações de interconexão e diálogo entre uma dimensão orgânica das formas e uma dimensão inorgânica das forças em meio à exploração somática. Trata-se, como bem nos evidenciou Deleuze e Guattari (1999), de abrir a dimensão do corpo-organismo ao plano das forças afetivas e sensíveis sem o anular ou destruir. A metodologia somática do BMC propõe uma experimentação do corpo tomando-o como um território organizado por meio das estruturas orgânicas e arquitetônicas de músculos, ossos, líquidos, órgãos, pele, em suma, sistemas e tecidos. Nesta prática recorre-se às representações correntes do corpo presentes em atlas anatômicos, protótipos de esqueleto e esquemas que evidenciam localizações e correlações possíveis entre partes do corpo em sua arquitetura interna.

Estas representações concernentes a dados biológicos, fisiológicos e arquitetônicos funcionam como alicerces para as experimentações do corpo e a consequente emergência de sensações cinestésicas, táteis e motoras além da eclosão de um imaginário encarnado. Assim, primeiramente identifica-se e diferencia-se o território estável do corpo organizado, reconhece-se suas estruturas, suas localizações, suas formas, suas inter-relações, e inclusive, suas funções a nível biológico e orgânico. No entanto, estes marcos anátomo-fisiológicos têm por função demarcar os distintos territórios corpóreos para, em seguida, possibilitar um mergulho em suas dinâmicas diferenciadas de fluxos, vibrações, densidades, rarefações, ritmos e velocidades.

A segunda pista é a "Modulação das Sensações". A partir da configuração desta geografia demarcada por referências anatômicas, fisiológicas, orgânicas, como também arquitetônicas, ${ }^{11}$ põe-se em movimento um território vital, múltiplo e vibrátil. A partir de então, o corpo é experimentado em sua potência performativa por meio de processos de modulações e variações no nível das matérias qualitativas. A segunda pista consiste então numa operação de modulação das matérias do corpo por meio do trabalho das sensações, estas podendo ser cinestésicas, táteis, motoras, entre outras.

Tal operação de modulação ocorre numa zona instável da matéria. Ao atingir esta zona, a matéria pode se evidenciar em seus traços de singularidade e expressão. O acesso a esta zona instável da matéria só se dará a partir do momento em que se desfaz minimamente a dimensão organismo da matéria, promovendo interconexões entre as dimensões extensiva e intensiva do corpo. Todo um trabalho somático ao nível dos pré-movimentos, pré-sentidos e pré-percepções auxiliará na desconstrução de representações cristalizadas do corpo, como também nas pré-concepções de hábitos perceptivos, sensitivos e motores.

O pesquisador e dançarino Hubert Godard (1998) afirma que há alguma coisa que antecipa todo e qualquer movimento ou gesto no espaço. Segundo ele o esquema corporal $^{12}$ consiste então numa primeira fase fundamental a toda percepção e todo gesto, já que a maneira como nos orientamos no espaço definirá a qualidade de nossos gestos e modos perceptivos. Portanto, anteriormente a execução de um gesto ou iniciação de um movimento há toda uma multiplicidade de movimentos internos do corpo chamados por ele de pré-movimento. O pré-movimento apóia-se sobre o esquema corporal e antecipa tanto nossas ações como nossas percepções. Ele age por meio dos músculos tônicos posturais, também chamados músculos gravitacionais, responsáveis pelos modos de orientação do corpo no espaço. O pré-movimento atua conjuntamente às pré-concepções, já que o pré-movimento, compreendido como microajustamentos anteriores ao

\footnotetext{
Na abordagem somática Bartenieff Fundamentals, é possível reconhecer (como em Rudolf Laban) o relacionamento do corpo com o espaço, na medida em que o corpo é percebido como uma arquitetura tridimensional, onde é possível notar as tensões diagonais e as relações contralaterais do corpo. A "arquitetura do corpo interno" é evidenciada por meio dos princípios de movimento que sublinham os exercícios propostos por Bartenieff, como por exemplo, as Conexões Ósseas. Estas consistem nas relações entre os marcos ósseos do corpo que criam verdadeiras formas geométricas internas. Como afirma Fernandes (2006), com base nesta arquitetura interna é possível ir para o espaço externo.

${ }^{12}$ Segundo Godard (2006) o esquema corporal, ou ainda esquema postural, repousa sobre um sistema de funções motoras que operam de modo pré-reflexivo, sem a atuação de uma intenção ou representação consciente, gerando nossos movimentos no espaço de modo automático sem a necessidade do monitoramento da consciência. $\mathrm{O}$ esquema corporal serve de tela de fundo às coordenações dos gestos e movimentos, às percepções e à expressividade.
} 
ato de se mover, encontra-se intimamente relacionado a hábitos perceptivos e posturais. Faz-se importante esclarecer que estes microajustamentos dizem respeito a uma composição plástica de verdadeiros "coletivos de unidades motoras", os músculos tônicos gravitacionais, que a partir dos hábitos e rotinas de movimento e percepção podem cristalizar sua atuação e perder sua plasticidade tornando-se repetitivos e automatizados.

Assim, uma vez desorganizados estes condicionamentos perceptivos, sensitivos e motores torna-se possível a eclosão de uma zona de contágio com uma materialidade energética, vital e instável - campo de forças e fluxos. Ao atingir o regime inventivo das matérias pode-se experimentar devires sensíveis do corpo em deformações intensivas. Por meio deste processo as formas sensíveis eclodem como composição de forças nos materiais.

A terceira pista é o "Imaginário Encarnado". Este nada mais é do que um acoplamento matéria-sensação-imagem. Ao atingir a zona instável da matéria evidencia-se uma potência sensitivo-imagética da própria matéria-corpo. Assim, por meio dos procedimentos práticos somáticos, num esforço de acessar a matéria-corpo, (seja ela, linhas ósseas, glândulas, fluidos ou órgãos) parte-se de imagens representativas das estruturas corpóreas. Estas imagens funcionam como trampolim para o mergulho na matéria-corpo. Ao mergulhar na materialidade corpórea e fazer contato com suas sensações, tem-se a chance de experimentar imagens vividas em meio à exploração somática. É possível aqui diferenciar duas qualidades de imagem: uma imagem-representação e uma imagem-sensação.

As imagens-representação constituem imagens abstratas e mentais exteriores à experiência corpórea. Estas estão relacionadas ao plano transcendente de organização. As imagens vividas em meio à experiência são chamadas aqui de imagens-sensação. Diferentemente da imagem-representação, a imagem-sensação não é relegada ao plano das representações como um suporte abstrato, mas antes ela possui em si mesma uma realidade material. Ela está relacionada ao plano imanente dos afetos e das forças. Estas imagens-sensação eclodem juntamente ou posteriormente à modulação das sensações. São imagens que surgem em meio às afecções do corpo. Desse modo, na prática somática, é possível partir de imagens-representação e chegar às imagens-sensação. $\mathrm{O}$ imaginário encarnado é essa potência imaginativa ativa presente no nível micro celular do corpo como também no nível macro dos órgãos, tecidos e sistemas.

Nomeamos aqui a quarta pista, a "Intencionalidade da Matéria e Estados do Corpo Modificado”. Trata-se da iniciação do movimento no espaço a partir da motivação interna das próprias matérias expressivas desprendidas da intencionalidade voluntária de um Eu-indivíduo. As dinâmicas de toque ou movimento podem levar a um acesso direto às qualidades energéticas materiais do corpo. A partir do trabalho somático no nível dos pré-movimentos, pré- sentidos e pré-percepções, abre-se uma pausa na intencionalidade objetiva de um Eu, permitindo o desmontar de esquemas sensório-motores habituais e suas funções tônicas.
Nesta pausa é possível adentrar as diversas paisagens da matéria-corpo. Trata-se de um verdadeiro convite à alteridade da matéria. Esta ganha força de expressão guiando o movimento no espaço exterior. Portanto, ao diminuir a intencionalidade objetiva, uma intencionalidade da matéria advém. Segundo Godard (1994), toda modificação produzida na relação proprioceptiva, exteroceptiva, e incluo aqui também, interoceptiva modifica imediatamente a função tônica de organização dos gestos. Por sua vez, a modificação tônica transforma imediatamente o estado do corpo, ou vice versa. Segundo Godard, a função tônica é contagiosa. Ao afirmar a mesma enquanto "função tônico-expressiva" e "tônico-afetiva" poder-se-ia então pensar que ela produz contágios em sua potência afetiva.

Desse modo, é possível também afirmar que ao diminuir a intencionalidade de um Eu-indivíduo e mergulhar nas qualidades afetivas e energéticas da matéria, toda uma modificação da função tônica ocorre, gerando mudanças no estado de presença do corpo. É possível reconhecer que, em geral, os movimentos guiados por uma intencionalidade qualitativa da matéria vêm acompanhados de modificações do estado geral de presença do corpo, ou, se preferirmos, um "estado do corpo modificado".

A quinta pista chamamos "Atenção Introspectivo-Receptiva". Constitui o desenvolvimento de uma atitude introspectiva ao corpo sem, no entanto, perder a conexão com o meio externo. A realização dos procedimentos somáticos em torno da propriocepção, exterocepção e interocepção são realizados por meio do foco interno numa atitude receptiva aos estímulos provenientes tanto do meio interno quanto externo. Portanto, ainda que o foco seja interno, desenvolve-se uma atitude perceptiva às informações sensíveis que entram e saem. Além das informações sensíveis é possível reconhecer as relações espaciais entre partes do corpo, suas conexões, como também, suas relações (crescendo/abrindo/desdobrando e/ou encolhendo/ fechando/dobrando). A partir desta atenção pode-se então perceber e acompanhar as variações dos estados do corpo. Uma verdadeira capacidade de escuta se desenvolve, além de uma capacidade de mergulho aos estados nascentes da matéria enquanto campo de forças e fluxos.

A sexta pista, o "Corpo-Alteridade", diz respeito às experimentações de um corpo-outro para além do corpo identitário e habitual, ou ainda, a produção da alteridade no próprio corpo. Trata- se então de acessar uma dimensão inventiva e criativa da própria materialidade corpórea. Corpo e espaço em dinâmica relacional mútua de co-criação se apresentam como territórios plásticos de uma geografia mutante. Eis que, a partir das experimentações sensíveis, o corpo objetivo cede lugar a uma materialidade corpórea em constante processo de metamorfose.

A partir dos procedimentos de toque e movimento no nível do pré-movimento, pré-sentidos e pré-percepção é possível atingir um corpo aberto em comunicação com outros corpos e o meio. Na medida em que as fronteiras porosas do corpo se alargam, a possibilidade de encontro direto com o outro se faz presente evidenciando uma zona de contágio. Nesta zona, vale ressaltar as potências do corpo de afetar e ser afetado, através das quais as qualidades 
intensivas entre as matérias se misturam. Por meio destas misturas o corpo se põe em devir: devir-animal, devir-vegetal, devir-mineral, devires-imperceptíveis, e outros.

Os procedimentos somáticos (toque celular ${ }^{13}$ e movimento) possibilitam um encontro intensivo do corpo com suas próprias materialidades. O corpo então finalmente atinge uma zona de contágio afectivo com os tecidos, líquidos, órgãos e sistemas que o compõem. Um devir-alteridade do próprio corpo se faz possível na medida em que um modo organizativo e representativo habitual de suas matérias (tecidos, órgãos, sistemas) se desfaz. Eis que um devir-alteridade da matéria pode estimular outros devires do corpo.

E finalmente, a sétima pista, a "Cartografia do Corpo Afetivo" nada mais é do que a construção de um mapa afetivo do corpo a partir da possibilidade de habitação da sua geografia interna. Esta geografia interna corpórea é feita de paisagens qualitativas: texturas, densidades, rarefações, pesos, velocidades, lentidões, vibrações energéticas, sonoridades, imensidões, espaços ínfimos. Ao explorar o ambiente corpo, a cada novo percurso pela geografia interna, uma nova paisagem qualitativa e mutante se apresenta. Na medida em que o corpo se experimenta em suas qualidades sensíveis e energéticas, à medida que um novo esquema sensório-motor é incorporado, um novo mapa afetivo se desenha e se integra. Esse mapa afetivo do corpo é também intitulado cartografia.

Trata-se da compreensão do corpo enquanto território flexível feito de paisagens materiais qualitativas que encerram em si a potência de afetar e ser afetado. A partir dos procedimentos somáticos de experimentação de um corpo sensível e em movimento constante, é possível então percorrer este território plástico e, a cada percurso, desenvolver uma nova cartografia do corpo. Esta nova cartografia pode significar a ampliação de uma cartografia já existente. De fato, nunca se chega ao fim de uma cartografia do corpo. Esta consiste num processo de composição ético-estético-político constante e infinito. Portanto, pode-se diferenciar aqui a cartografia do corpo afetivo do mapa anatômico.

O mapa anatômico é o mapa das representações formais do corpo enquanto topologia extensiva. Ele é estável e exterior à própria experiência. Já a cartografia do corpo afetivo é um mapa dos campos de forças e fluxos energéticos da matéria-corpo enquanto topologia extensivo-intensiva. Ele é instável e imanente à própria experiência, ou seja, ele se atualiza na experiência vivida. Cada um cria para si a sua própria cartografia do corpo afetivo. Nos procedimentos somáticos, recorre-se frequentemente ao mapa anatômico no intuito de acessar esta realidade intensiva da matéria. No entanto, o apoio em um discurso organicista acompanhado de um imaginário biológico, longe de buscar uma garantia cientificista de verdade, opera a constituição de um plano de experimentação do corpo no qual o mesmo se constitui por uma substância aberta, plural e em ontogênese constante.

\footnotetext{
${ }^{13} \mathrm{O}$ Toque Celular é um procedimento prático realizado nas aulas de BMC. Uma qualidade de toque receptiva e acolhedora, uma escuta tátil.
}

Portanto, as informações e imagens de cunho anátomo-fisiológico têm por função demarcar territórios, pondo-os em ação, em circunstâncias de modulação e variação intensiva da matéria corpórea. Desse modo, quanto mais tem-se a chance de mergulhar nos umbrais intensivos da matéria, mais e mais é possível enriquecer e ampliar o mapa afetivo. Este funcionará como uma ferramenta de acesso às entradas e saídas na matéria-corpo possibilitando o manejo das qualidades expressivas de cada matéria específica (sistema, tecido, órgãos, fluidos, células). Uma vez acessadas, cada matéria específica funcionará como uma ferramenta de acesso ao experimentador. Este poderá modular estas diferentes qualidades em formas, gestos, movimentos e estados modificados do corpo em sua relação com o espaço.

Conforme afirmamos no início deste texto, as pistas somáticas para um estudo da corporeidade não intencionam apresentar um modelo mas sim, compartilhar reflexões advindas de um campo investigativo norteado pelas buscas do corpo em experimentação de si. Tal busca esteve ancorada na convicção de que era preciso, ainda nos dias atuais, dar continuidade à redescoberta do corpo iniciada desde meados do século XIX pelas inquietações de pensadores, filósofos, artistas e educadores somáticos. Por sua vez, tal convicção se encontra baseada no reconhecimento de que as representações reducionistas em torno do corpo objetivo, pragmático e homogêneo ainda se fazem presentes e atuantes nos diversos planos da vida, em meio a um sistema de poder e controle social perverso, narcisista e massificante. Assim, a partir destas convicções procuramos buscar o corpo em sua vitalidade irredutível e desprendida dos protocolos, das verdades pré-estabelecidas e das compreensões absolutas.

\section{Referências}

BERNARD, M. De la creation choregraphique. Paris: Recherches - Centre National de la Danse, 2001.

CAETANO, P. L. O corpo intenso nas Artes Cênicas: procedimentos para o Corpo sem Órgãos a partir dos Bartenieff Fundamentals e do Body Mind Centering. 2012. Tese (Doutorado)-Universidade Federal da Bahia, Salvador, 2012.

COHEN, B. B. Uma Introdução ao Body Mind Centering. Cadernos do Gipe-Cit, - UFBA, Salvador, n. 18, p. 36-49, abr. 2008.

COHEN, B. B. Le processus d'incorporation. In: l'une à l'autre. Bruxelles: Contredanse, 2010. p. 66-67.

DELEUZE, G.; GUATTARI, F. Mil platôs: capitalismo e esquizofrenia. Rio de Janeiro: Editora 34, 1999. v. 3.

FERNANDES, C. O corpo em movimento: o sistema Laban/ Bartenieff na formação e pesquisa em artes cênicas. São Paulo: Annablume, 2006.

FORTIN, S. Educação somática: novo ingrediente da formação prática em dança. Cadernos do Gipe-Cit - UFBA, Salvador, n. 2, p. 42-57, fev. 1999.

GIL, J. Movimento total: o corpo e a dança. São Paulo: Iluminuras, 2004.

GODARD, H. Le geste manquant. Revue Internationalle de Psychanalyse, Paris, n. 5, p. 63-75, jun. 1994. 
GODARD, H. Le geste et sa perception. In: La danse au XXeme Siècle. Paris: Bordas, 1998. p. 224-229.

GODARD, H. Des trous noirs. Nouvelles de Danse Contredanse, Bruxelles, n. 53. p. 56-75. 2006.

HANNA, T. The field of somatics. SOMATICS: MagazineJournal of the Bodily Arts and Sciences, v. I, n. 1, Autumn 1976. Disponível em: <https://somatics.org/library/htlfieldofsomatics $>$. Acesso em: 2 set. 2016.

Recebido em: 11 de janeiro de 2017 Aceito em: 2 de junho de 2017 